\title{
Winter diet and roosting site use of urban roosting Long-eared Owls (Asio otus), and the change in the species' population size in Southeast Hungary ${ }^{\times}$
}

\author{
László Bozó ${ }^{*}$, Tamás RutKAI², András István Csathó ${ }^{3} \&$ Erna \\ BOZÓNÉ BORBÁTH ${ }^{4}$
}

${ }^{\times}$Presented at $2^{\text {nd }}$ Hungarian Owl Research Conference held in Pécs on $11^{\text {th }}$ September 2020.

Received: September 16, 2020 - Revised: October 21, 2020 -Accepted: October 27, 2020

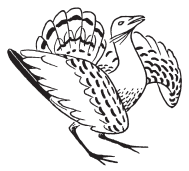

Bozó, L., Rutkai, T., Csathó, A. I. \& Bozóné Borbáth, E. 2020. Winter diet and roosting site use of urban roosting Long-eared Owls (Asio otus), and the change in the species' population size in Southeast Hungary. - Ornis Hungarica 28(2): 1-18. DOI: 10.2478/orhu-2020-0013

\begin{abstract}
The Long-eared Owl (Asio otus) was chosen as the bird of the year in Hungary by BirdLife Hungary in 2020 to pay more attention to this species. In the present study, we analysed the data collected on the food, changes in the population and the use of the roosting sites of the owls wintering Southeast-Hungary. A total of 4,683 pellets were collected in four winter seasons between 2016 and 2020, of which 5,265 prey animals were identified. We counted the individuals roosting in the winter roosting sites, and from their maximum number we estimated the local population change of the species as well as the success of the breeding. For this, we also used roadkill data from the nearby town, Battonya.

The diet of Long-eared Owls in the study area was similar to that observed in other parts of the Carpathian Basin. The smaller differences were mainly due to the different geographical distribution of different prey species. We also identified some species previously having no or very few data, thus we confirmed their stable presence in the area. Different weather factors within the season did not effect owls' diet. The most varied diet was found in the warmest, least snowy winter. Comparing the feeding data with the data from the 1960s and 1970s, it can be seen that the proportion of preys changed significantly. The proportion of House/Steppe Mice decreased by an order of magnitude, while that of rats increased by the same amount over time. The most likely reasons for this may be changes in agricultural cultivation or local demographic conditions (depopulation). In the 2018/19 season, the proportion of Common Vole in the pellets was much higher than in any other years, suggesting this year's gradation of the species. The pellets collected in different roosting sites close to each other typically had the same proportions of prey animals.

The maximum number of birds observed at the roosting sites did not correlate with the weather of the given season, but was probably related to the effectiveness of the previous breeding season.

The population of the species decreased compared to the early 2000's based on the number of roosting individuals. This may be due to a decline in crow populations. It should be noted, however, that according to both the roadkills in Battonya and the maximum number of the roosting individuals in Kevermes, this drastic decline came to a halt in 2010 s.
\end{abstract}

Keywords: bird ringing, Microtus arvalis, Mus spicilegus, owl pellets, roadkills

Összefoglalás Az erdei fülesbaglyot (Asio otus) a Magyar Madártani és Természetvédelmi Egyesület 2020-ban az év madarának választotta, hogy nagyobb figyelem irányuljon erre a fajra. Ebben a cikkben a délkelet-magyarországi Kevermesen telelő erdei fülesbaglyok táplálékáról, állományváltozásáról, illetve nappalozóhely-használatáról gyüjtött adatokat dolgoztuk fel. A táplálkozástani vizsgálatokhoz összesen 4683 köpetet gyüjtöttünk négy téli szezonban 2016 és 2020 között, amelyekből 5265 zsákmányállat került elö. Megszámoltuk a nappalozóhelyeken gyülekező egyedeket, amelyeknek a maximális számából következtettünk a faj helyi állományára, illetve a költés sikerességére is. Ehhez felhasználtunk a közeli Battonya településről származó elütési adatokat is. 
ORNIS HUNGARICA 2020. 28(2)

Az erdei fülesbaglyok tápláléka a vizsgálati területen hasonló a Kárpát-medence más részein tapasztaltakhoz. A kisebb eltérések elsősorban a különböző zsákmányállat-fajok Kárpát-medencén belüli elterjedési viszonyai miatt adódtak. A köpetekben kimutattunk néhány olyan fajt is, amelyeknek eddig nem, vagy csak nagyon kevés adata volt a területen, és ezáltal igazolást nyert kisszámú, de stabil jelenlétük a térségben. A különböző időjárási tényezök a szezonon belül nem voltak hatással a baglyok táplálékára. A legváltozatosabb táplálékspektrum a legmelegebb, legkevésbé havas télen gyűjtött köpetekben volt. A táplálkozástani eredményeket összehasonlítva az 50-60 évvel korábbi adatokkal megállapítható, hogy a zsákmányállatok aránya szignifikánsan változott, így a güzü/házi egér aránya egy nagyságrenddel csökkent, míg a vándorpatkányé ugyanennyivel nőtt az eltelt időben. Ennek legvalószínübb okai a mezőgazdasági művelésben bekövetkezett változások, illetve a helyi demográfiai viszonyok (elnéptelenedés) lehetnek. A 2018-2019-es szezonban jóval magasabb volt a mezei pockok aránya a táplálékban, ami a faj ez évi gradációjára utal. A különböző, egymáshoz közeli nappalozóhelyeken gyüjtött köpetekben jellemzően ugyanolyan arányban voltak jelen a különböző zsákmányállatok.

A gyülekezőhelyeken észlelt maximális példányszámok nem mutattak összefüggést az adott szezon időjárásával, hanem valószínűleg az előző költési szezon eredményességével voltak kapcsolatban.

A faj állománya a gyülekezőhelyeken összegyűlt egyedek száma alapján csökkent a 2000-es évek elejéhez képest. Ennek hátterében a varjúfélék állományának csökkenése állhat. Megemlítendő ugyanakkor, hogy mind a battonyai elütési adatok, mind a kevermesi gyülekezőhelyen számolt maximális példányszámok alapján a 2010es években ez a drasztikus csökkenés megállt.

Kulcsszavak: madárgyürüzés, Microtus arvalis, Mus spicilegus, bagolyköpet, elütés

${ }^{1}$ Department of Systematic Zoology and Ecology, Eötvös Loránd University, 1117 Budapest, Pázmány Péter sétány 1/C. Hungary

24484 Ibrány, Tisza utca 12. Hungary

${ }^{3} 5830$ Battonya, Somogyi Béla utca 42/A. Hungary

${ }^{4}$ South Békés Nature Conservation Society, 5744 Kevermes, Jókai utca 61. Hungary

* corresponding author, e-mail: bozolaszlo91@gmail.com

\section{Introduction}

The Long-eared Owl (Asio otus) occures in most of Eurasia, North and East Africa and also in North America (Birdlife International 2020). Populations breeding at different points in the distribution area have different migratory strategies. Northern poopulations are migratory, while the tendency to migrate decreases from north to south (Glutz von Blotzheim \& Bauer 1980). Most of the Hungarian breeding population is resident. In winter, small numbers of individuals nesting in the north also appear in the Carpathian Basin (Laczik \& Sebe 2009). In winter, they roost in flocks in parks, cemeteries, gardens and streets of populated areas (Kalotás 1998, Kovács 2015). They prefer evergreens (pines, thujas) but can also roost on amber-covered acacia and other deciduous trees (Kovács 2015). These roosting sites are usually located in wind-protected areas, often next to buildings, but can also change during the season as the weather changes. Their winter site fidelity is surprisingly high (Gyovai 1986). Because the birds that use the resting place typically come from the surrounding areas, traditional roosting places usually do not change over the years (Gyovai 1986, Laczik \& Sebe 2009).

The species feeds primarily on small mammals, in Hungary mainly on Common Voles (Microtus arvalis). This is complemented by the local occurrence of the Wood Mouse (Apodemus sp.), The Eurasian Harvest Mouse (Micromys minutus) and the House/Steppe Mouse (Mus musculus / spicilegus) (Schmidt 1973). Other rodents, shrews (Crocidura sp.), European Moles (Talpa europaea), rats (Rattus sp.), Water Voles (Arvicola terrestris), Least 
Weasels (Mustela nivalis) and insects are very rarely predated (Kalotás 1998). The proportion of bird preys is associated with snow cover (Schmidt 1965).

Studies on the feeding of the Long-eared Owls have been carried out in the Carpathian Basin in high number. The literature dealing with this was collected and summarized by Kalivoda (1999a), but there are also publications from subsequent years (e.g. Molnár 2010, Szilágyi-Bónizs et al. 2016). Such studies also took place in the south-southeastern part of Békés County in the 1960s and 1970s (Schmidt 1973, 1974a, 1980). In contrast, only a few dealt with the wintering and roosting habits of the species (Gyovai 1986, Pótis 1992, Végvári \& Konyhás 2003, Kovács 2015, Gyovai 2020).

The species is considered to be a regular breeder in Kevermes, and have a winter roosting site in the center of the village, probably dating back several decades (Bozó 2017). Therefore, we had the opportunity to examine the feeding and population changes of the species. In addition, based on the number of birds appearing annually in the roosting sites and the number of roadkilled individuals found, we estimated the long-term change in the population of the Long-eared Owl in the study area.

\section{Material and methods}

Owl pellets were collected in four winter seasons (2016/17, 2017/18, 2018/19 and 2019/20). Pellets were typically collected at intervals of one to a maximum of two weeks, except in the winter of 2016/17, when pellets were collected only once at the end of the season. The first collection of the season covered a wider time interval from the start of roosting. Pellets were collected regularly from two different locations: Kevermes park (hereafter: the park)

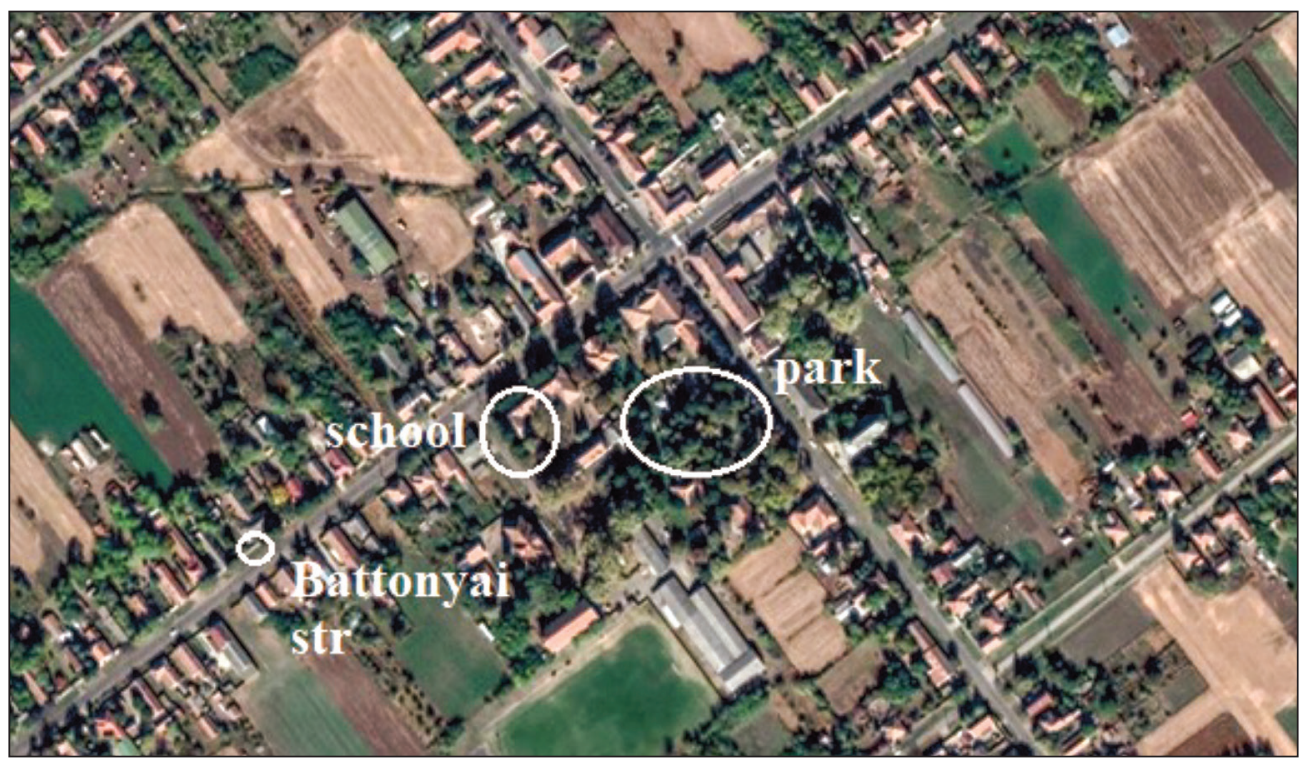

Figure 1. The locations of pellet collections in Kevermes 1.ábra A köpetek gyűjtésének helyszínei Kevermesen 
and 100 meters away in the garden of the school (hereafter: school) (Figure 1). In both places, approx. 70-year-old common spruce (Picea abies) dominate, however, most owls in the park have roosted on a prickly spruce (Picea pungens) with a more closed foliage. The birds occasionally migrated to other parts of the village. These roosting sites were always located on common birch trees (Betula pendula), from one of which we managed to collect a larger amount of pellets in 2017/18.

The identification of small mammals in pellets was based on Ujhelyi (1989), while the identification of birds was based on Kessler (2015) and Ujhelyi (2016). In some cases, the bird species found could not be identified on species level, therefore, they were grouped according to their size. Wood Mouse species (Apodemus sp.) were handled together with the exception of the Striped Field Mouse (Apodemus agrarius).

Chi-squared test was used to compare the proportion of different preys in pellets collected in different roosting sites and periods. The proportion of prey animals was also compared with the published literature from the Carpathian Basin (Greschik 1911, Lambrecht 1914, Schaefer 1935, Köves \& Schmidt 1964, Csizmazia 1966, Papp 1971, Schmidt \& Topál 1971, Marián \& Marián 1973, Schmidt 1973, 1974a, 1974b, 1978, 1980, 1987, Andrési \& Sódor 1981, 1987, Nagy 1982a, 1982b, Bessenyei et al. 1983, Molnár 1983, 1994, Varga 1983, 1984, 1987, Ács 1986, Dániel et al. 1986, Endes 1986, Kalivoda 1987, 1994, 1999b, Mátics 1990, Ujhelyi 1991, Tóth 1992, Csathó \& Csathó 2009, Molnár 2010, SzilágyiBónizs et al. 2016). These literature sources were collected on the basis of the summary work of Kalivoda (1999a) and on the basis of the papers published after that date. Because owl pellet surveys were also conducted in the area in the 1960s and 1970s (Schmidt 1980), we were able to compare our results with these 50-60-year-old data.

We used Spearmans's rank correlation to relate the number of the most common preys with the different weather variables. The number of prey animals identified in the pellets collected at the given time was compared with the mean minimum, maximum and average temperature values of the period passed from the previous collection, as well as with the maximum snow thickness recorded in the same period. All temperature data were gathered from the website of the National Centers for Environmental Information (https://www.ncei. noaa.gov) and the website of the Hungarian Meteorological Society (https://www.met.hu).

The long-term changes of the local population of the species were studied with two methods. As they come to each roosting sites mainly from the nearby nesting places (Laczik $\&$ Sebe 2009), the local population may also be estimated on the basis of the number of birds at winter roosting sites. Therefore, we have been counting roosting owls every year since 2013. A counting during the winter of 2002/03 was carried out by the first author, which was used as a baseline in the present analysis for comparisonswith the more recent seasons. Countings were not made at regular intervals (every one or two weeks), but for the same duration (half an hour). For further analyses, we used the maximum number of individuals for the given season. We examined whether there was a correlation between the maximum annual numbers at the roosting site and the total amount of snow that fell in a given season, the average temperature between November and March, and the number of snowy days.

The other method used for the estimating possible changes in the species' population was based on roadkilled individuals. We collected detailed data in a town with similar 
geographical features (Battonya) located $19 \mathrm{~km}$ from Kevermes. Between 2012 and 2019, we carried out roadkill surveys in the entire administrative area of Battonya (14,577 hectares). There are four busy roads in the outer area of Battonya: Kovácsházi road (length: 8.4 $\mathrm{km})$, Dombegyházi road $(4.3 \mathrm{~km})$, Tornyai road $(5.0 \mathrm{~km})$ and Mezőhegyesi road $(3.4 \mathrm{~km})$ (Csathó \& Csathó 2009). The surveys were carried out in most cases once a month during the whole year. Estimated date of the collision together with its location along the road was noted for each individual. We used Spearmans's rank correlation to relate the number of the roadkilled Long-eared Owls after the months of the fledging (May - September) with the seasonal percentage of the Common Vole found in the pellets, and also to the annual maximum numbers of the roosting Long-eared Owls in Kevermes. Statistical analyses were carried out using Past 3.14 (Hammer et al. 2001).

\section{Results}

The proportion of prey animals of the Long-eared Owl found in the literature from the Carpathian Basin are summarized in Table 1.

A total of 4,683 pellets were analyzed, in which 5,265 individuals of 19 different species of mammals and birds were identified (Table 2). The most common prey animals were the Common Vole (72.4\%), Wood Mice (21.9\%), Striped Field Mouse (2.4\%) and House/ Steppe Mouse (1.1\%). We also found Hazel Dormouse (Muscardinus avellanarius), European Hamster (Cricetus cricetus), European Pine Vole (Microtus subterraneus) and Eurasian Harvest Mouse. The most common bird species found in the pellets was the Eurasian Tree Sparrow (Passer montanus) $(0.7 \%)$. There was no significant difference between the proportion of the preys in our samples and the data collected from the Carpathian Basin $\left(\chi^{2}=\right.$ $8.818, \mathrm{p}=0.184)$. The proportion of different preys from the pellets collected in different roosting sites did not differed significantly either $\left(\chi^{2}=0.170, p=0.982\right)$. Comparing the results of the pellet analyses in Békés County in the 1960s and 1970s with the results obtained by us, we found a significant difference $\left(\chi^{2}=14.841, p=0.011\right)$. In the case of the House/ Steppe Mouse, we detected significantly smaller amount in the present study, while the proportion of rats increased significantly (Table 3).

No correlation was found between the temporal distribution of prey animals and temperature or the thickness of snow cover (Table 4).

The first wintering individuals usually appeared at the roosting sites in October (occasionally in September), and typically stayed until mid-March (occasionally early April) (Table 5 ). Of the winter seasons examined, the highest number of birds observed at one time was 120 in 2002/03, while the lowest (11 birds) in 2012/13. There was no significant relationship between the maximum number of birds observed and the average temperature $(R=-0.31$, $\mathrm{p}=0.41)$, the number of snowy days $(\mathrm{R}=0.13, \mathrm{p}=0.73)$ and the total amount of snow during the whole winter season. $(\mathrm{R}=0.03, \mathrm{p}=0.96)$.

There was no significant correlation between the annual distribution of roadkilled individuals in Battonya during the breeding season and the maximum number of owls observed in the following wintering season $(\mathrm{R}=0.18, \mathrm{p}=0.67)$. The proportion of Common Voles 
Table 1. The prey animals of the Long-eared Owl in the Carpathian Basin (summarized data based on the literature, see Material and methods)

1. táblázat $\mathrm{Az}$ erdei fülesbagoly zsákmányállatai a Kárpát-medencében (irodalmi adatok alapján összesítve, lásd Material and methods)

\begin{tabular}{|c|c|}
\hline \multicolumn{2}{|c|}{ Rodentia } \\
\hline Microtus arvalis & $62.52 \%$ \\
\hline Apodemus sylvaticus & $12.74 \%$ \\
\hline Mus musculus & $4.41 \%$ \\
\hline Microtus agrestis & $2.52 \%$ \\
\hline Microtus subterraneus & $2.17 \%$ \\
\hline Micromys minutus & $1.97 \%$ \\
\hline Apodemus agrarius & $0.87 \%$ \\
\hline Myodes glareolus & $0.47 \%$ \\
\hline unid. Mouse & $0.43 \%$ \\
\hline Microtus oeconomus & $0.33 \%$ \\
\hline Arvicola amphibius & $0.31 \%$ \\
\hline Arvicolinae & $0.19 \%$ \\
\hline Rattus sp. & $0.08 \%$ \\
\hline \multicolumn{2}{|c|}{ Soricidae } \\
\hline Sorex araneus & $0.51 \%$ \\
\hline Crocidura suaveolens & $0.28 \%$ \\
\hline Sorex minutus & $0.22 \%$ \\
\hline Crocidura leucodon & $0.22 \%$ \\
\hline Neomys fodiens & $0.14 \%$ \\
\hline Soricidae & $0.01 \%$ \\
\hline \multicolumn{2}{|c|}{ Chiroptera } \\
\hline Nyctalus sp. & $0.95 \%$ \\
\hline Pipistrellus nathusii & $0.95 \%$ \\
\hline Myotis blythii & $0.95 \%$ \\
\hline Plecotus austriacus & $0.95 \%$ \\
\hline Nyctalus noctula & $0.18 \%$ \\
\hline Chiroptera & $<0.01 \%$ \\
\hline \multicolumn{2}{|c|}{ Other Mammalia } \\
\hline Talpa europaea & $1.92 \%$ \\
\hline Muscardinus avellanarius & $<0.01 \%$ \\
\hline Lepus europaeus & $<0.01 \%$ \\
\hline unid. Mammalia & $<0.01 \%$ \\
\hline Mustela nivalis & $<0.01 \%$ \\
\hline Cricetus cricetus & $<0.01 \%$ \\
\hline Leporidae & $<0.01 \%$ \\
\hline \multicolumn{2}{|c|}{ Insecta } \\
\hline Geotrupidae & $<0.01 \%$ \\
\hline Melolonthinae & $<0.01 \%$ \\
\hline Carabidae & $<0.01 \%$ \\
\hline
\end{tabular}

\begin{tabular}{|l|r|}
\hline \multicolumn{2}{|c|}{ Aves } \\
\hline Passer domesticus & $0,89 \%$ \\
\hline Unid. Aves & $0,56 \%$ \\
\hline Passer montanus & $0,43 \%$ \\
\hline Turdus merula & $0,11 \%$ \\
\hline Carduelis carduelis & $0,11 \%$ \\
\hline Alauda arvensis & $0,06 \%$ \\
\hline Linaria cannabina & $0,06 \%$ \\
\hline Emberiza citrinella & $0,06 \%$ \\
\hline Parus major & $0,04 \%$ \\
\hline Coccothraustes coccothraustes & $0,04 \%$ \\
\hline Parus sp. & $0,03 \%$ \\
\hline Passer sp. & $0,03 \%$ \\
\hline Acanthis flammea & $0,03 \%$ \\
\hline Emberiza calandra & $0,03 \%$ \\
\hline Glareola cristata & $0,02 \%$ \\
\hline Sylvia sp. & $0,02 \%$ \\
\hline Turdus sp. & $0,02 \%$ \\
\hline Fringilla coelebs & $0,02 \%$ \\
\hline Chloris chloris & $0,02 \%$ \\
\hline Unid. Passeriformes & $0,01 \%$ \\
\hline Pica pica & $0,01 \%$ \\
\hline Cyanistes caeruleus & $0,01 \%$ \\
\hline Hirundo/Delichon sp. & $0,01 \%$ \\
\hline Regulus regulus & $0,01 \%$ \\
\hline Serinus serinus & $0,01 \%$ \\
\hline Coturnix coturnix & $<0.01 \%$ \\
\hline Rallus aquaticus & $<0.01 \%$ \\
\hline Certhia sp. & $<0.01 \%$ \\
\hline Sitta europaea & $<0.01 \%$ \\
\hline Troglodytes troglodytes & $<0.01 \%$ \\
\hline Turdus pilaris & $<0.01 \%$ \\
\hline Erithacus rubecula & $<0.01 \%$ \\
\hline Pyrrhula pyrrhula & $<0.01 \%$ \\
\hline Emberiza schoeniclus & \\
\hline & \\
\hline Pelobates fuscus & \\
\hline
\end{tabular}


Table 2. Time and location of the pellet collections during the research period, and the number of prey animals found in the pellets. The abbreviations of the collection sites are as follows: par: park, sch: school, bat: Battonyai street. The abbreviations of prey animals are as follows: ARV: Microtus arvalis, SYL: Apodemus sylvaticus, MUS: Mus musculus, AGR: Apodemus agrarius, MIN: Micromys minutus, RAT: Rattus sp., LEU: Crocedura leucodon, CRI: Cricetus cricetus, AVE: Muscardinus avellanarius, SUB: Microtus subterraneus, DE: Streptopelia decaocto, MO: Passer montanus, DO: Passer domesticus, CA: Carduelis carduelis, TU: Turdus sp., EM: Emberiza sp., AL: Motacilla alba, PA: Parus sp., SV: Sylvia sp., SB: small bird, 21. large bird, 22. unidentified bird

2. táblázat A kutatási időszakban összegyüjtött bagolyköpetek gyüjtési ideje, helye, ill. a köpetekben talált zsákmányállatok száma. A gyüjtés helyének rövidítései a következők: par: park, sch: iskola, bat: Battonyai utca. A zsákmányállatok rövidítései a következők: ARV: Microtus arvalis, SYL: Apodemus sylvaticus, MUS: Mus musculus, AGR: Apodemus agrarius, MIN: Micromys minutus, RAT: Rattus sp., LEU: Crocedura leucodon, CRI: Cricetus cricetus, AVE: Muscardinus avellanarius, SUB: Microtus subterraneus, DE: Streptopelia decaocto, MO: Passer montanus, DO: Passer domesticus, CA: Carduelis carduelis, TU: Turdus sp., EM: Emberiza sp., AL: Motacilla alba, PA: Parus sp., SV: Sylvia sp., SB: kistestű madár, 21. nagytestű madár, 22. meghatározatlan madár

\begin{tabular}{|c|c|c|c|c|c|c|c|c|c|c|c|c|c|c|c|c|c|c|c|c|c|c|c|c|c|c|}
\hline 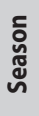 & ڤัّ & 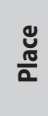 & 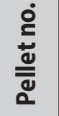 & $\frac{\stackrel{8}{c}}{\grave{\partial}}$ & खे & $\frac{1}{n}$ & ڤૂ & 원 & $\geqq$ & $\underset{\mathbb{\alpha}}{\stackrel{2}{c}}$ & 勇 & ণ্ড & 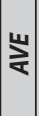 & $\stackrel{m}{\sim}$ & 㟔 & 올 & 이 & $\checkmark$ & $\vec{R}$ & 岃 & रे & $\Sigma$ & ৯े & ஸै & 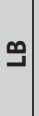 & $\infty$ \\
\hline \multirow{2}{*}{$\frac{N}{\frac{N}{\sigma}}$} & - & sch & 505 & 489 & 325 & 121 & 10 & 23 & 0 & 2 & 0 & 0 & 0 & 0 & 0 & 8 & 0 & 0 & 0 & 0 & 0 & 0 & 0 & 0 & 0 & 0 \\
\hline & - & par & 40 & 66 & 39 & 24 & 0 & 0 & 0 & 0 & 0 & 0 & 0 & 0 & 0 & 3 & 0 & 0 & 0 & 0 & 0 & 0 & 0 & 0 & 0 & 0 \\
\hline \multirow{10}{*}{$\frac{\infty}{\frac{\infty}{\pi}}$} & 8.12 .2017 & par & 40 & 33 & 25 & 4 & 1 & 1 & 1 & 0 & 0 & 0 & 0 & 0 & 0 & 1 & 0 & 0 & 0 & 0 & 0 & 0 & 0 & 0 & 0 & 0 \\
\hline & 15.12.2017 & par & 40 & 37 & 17 & 16 & 0 & 2 & 0 & 0 & 0 & 0 & 0 & 0 & 0 & 1 & 0 & 0 & 0 & 0 & 0 & 0 & 0 & 1 & 0 & 0 \\
\hline & 24.12.2017 & par & 40 & 46 & 26 & 16 & 1 & 1 & 1 & 0 & 0 & 0 & 0 & 0 & 0 & 1 & 0 & 0 & 0 & 0 & 0 & 0 & 0 & 0 & 0 & 0 \\
\hline & 31.12 .2017 & par & 40 & 44 & 28 & y & 0 & 2 & 2 & 1 & 0 & 0 & 0 & 0 & 0 & 0 & 2 & 0 & 0 & 0 & 0 & 0 & 0 & 0 & 0 & 0 \\
\hline & 07.01 .2018 & par & 40 & 36 & 16 & 13 & 0 & 2 & 1 & 0 & 0 & 0 & 0 & 0 & 0 & 1 & 1 & 1 & 0 & 0 & 0 & 0 & 0 & 0 & 1 & 0 \\
\hline & 20.01 .2018 & par & 40 & 39 & 21 & 13 & 0 & 1 & 3 & 0 & 0 & 0 & 0 & 0 & 0 & 1 & 0 & 0 & 0 & 0 & 0 & 0 & 0 & 0 & 0 & 0 \\
\hline & 03.02 .2018 & par & 53 & 47 & 34 & 8 & 1 & 3 & 0 & 0 & 0 & 0 & 0 & 0 & 0 & 0 & 0 & 0 & 0 & 0 & 0 & 0 & 0 & 0 & 0 & 1 \\
\hline & 11.02 .2018 & par & 8 & 8 & 8 & 0 & 0 & 0 & 0 & 0 & 0 & 0 & 0 & 0 & 0 & 0 & 0 & 0 & 0 & 0 & 0 & 0 & 0 & 0 & 0 & 0 \\
\hline & 06.03.2018 & par & 51 & 44 & 39 & 4 & 0 & 0 & 0 & 0 & 0 & 0 & 0 & 0 & 0 & 0 & 1 & 0 & 0 & 0 & 0 & 0 & 0 & 0 & 0 & 0 \\
\hline & 06.03 .2018 & bat & 100 & 114 & 51 & 53 & 2 & 3 & 0 & 2 & 1 & 0 & 0 & 0 & 0 & 1 & 0 & 0 & 0 & 0 & 0 & 0 & 0 & 0 & 1 & 0 \\
\hline \multirow{16}{*}{$\frac{\infty}{\infty}$} & 2 & par & 226 & 255 & 242 & 11 & 1 & 0 & 0 & 0 & 0 & 1 & 0 & 0 & 0 & 0 & 0 & 0 & 0 & 0 & 0 & 0 & 0 & 0 & 0 & 0 \\
\hline & 18.11.2018 & par & 200 & 286 & 273 & 8 & 3 & 1 & 0 & 0 & 0 & 0 & 1 & 0 & 0 & 0 & 0 & 0 & 0 & 0 & 0 & 0 & 0 & 0 & 0 & 0 \\
\hline & 09.12 .2018 & par & 130 & 142 & 124 & 12 & 0 & 5 & 0 & 0 & 0 & 0 & 0 & 0 & 0 & 1 & 0 & 0 & 0 & 0 & 0 & 0 & 0 & 0 & 0 & 0 \\
\hline & 25.12.2018 & par & 100 & 112 & 87 & 22 & 0 & 2 & 0 & 0 & 0 & 0 & 0 & 0 & 0 & 1 & 0 & 0 & 0 & 0 & 0 & 0 & 0 & 0 & 0 & 0 \\
\hline & 19.01.2019 & par & 150 & 422 & 333 & 77 & 2 & 9 & 0 & 0 & 0 & 0 & 0 & 0 & 0 & 0 & 0 & 0 & 0 & 0 & 0 & 0 & 0 & 1 & 0 & 0 \\
\hline & 02.02.2019 & par & 340 & 297 & 201 & 91 & 2 & 2 & 0 & 0 & 0 & 0 & 0 & 0 & 0 & 1 & 0 & 0 & 0 & 0 & 0 & 0 & 0 & 0 & 0 & 0 \\
\hline & 10.02 .2019 & par & 250 & 310 & 216 & 82 & 2 & 6 & 0 & 1 & 0 & 0 & 0 & 0 & 0 & 3 & 0 & 0 & 0 & 0 & 0 & 0 & 0 & 0 & 0 & 0 \\
\hline & 24.02.2019 & par & 266 & 266 & 199 & 58 & 3 & 3 & 0 & 0 & 0 & 0 & 0 & 0 & 0 & 0 & 1 & 0 & 0 & 0 & 0 & 0 & 0 & 2 & 0 & 0 \\
\hline & 28.10 .2018 & sch & 72 & 84 & 80 & 3 & 1 & 0 & 0 & 0 & 0 & 0 & 0 & 0 & 0 & 0 & 0 & 0 & 0 & 0 & 0 & 0 & 0 & 0 & 0 & 0 \\
\hline & 18.11.2018 & sch & 150 & 185 & 163 & 16 & 1 & 5 & 0 & 0 & 0 & 0 & 0 & 0 & 0 & 0 & 0 & 0 & 0 & 0 & 0 & 0 & 0 & 0 & 0 & 0 \\
\hline & 09.12 .2018 & sch & 52 & רד & 4 & 24 & 0 & 2 & 0 & 0 & 0 & 0 & 0 & 1 & 0 & 0 & 0 & 0 & 0 & 0 & 0 & 0 & 0 & 0 & 0 & 0 \\
\hline & 25.12 .2018 & sch & 100 & 111 & 97 & 13 & 1 & 0 & 0 & 0 & 0 & 0 & 0 & 0 & 0 & 0 & 0 & 0 & 0 & 0 & 0 & 0 & 0 & 0 & 0 & 0 \\
\hline & 19.01 .2019 & sch & 97 & 103 & 84 & 15 & 0 & 4 & 0 & 0 & 0 & 0 & 0 & 0 & 0 & 0 & 0 & 0 & 0 & 0 & 0 & 0 & 0 & 0 & 0 & 0 \\
\hline & 02.02 .2019 & sch & 45 & 4 & 26 & 20 & 0 & 1 & 0 & 0 & 0 & 0 & 0 & 1 & 0 & 0 & 0 & 0 & 0 & 0 & 0 & 0 & 0 & 0 & 0 & 0 \\
\hline & 10.02 .2019 & sch & 106 & 132 & 105 & 24 & 0 & 3 & 0 & 0 & 0 & 0 & 0 & 0 & 0 & 0 & 0 & 0 & 0 & 0 & 0 & 0 & 0 & 0 & 0 & 0 \\
\hline & 24.02 .2019 & sch & 73 & 85 & 70 & 14 & 0 & 0 & 0 & 0 & 0 & 0 & 0 & 1 & 0 & 0 & 0 & 0 & 0 & 0 & 0 & 0 & 0 & 0 & 0 & 0 \\
\hline
\end{tabular}




\begin{tabular}{|c|c|c|c|c|c|c|c|c|c|c|c|c|c|c|c|c|c|c|c|c|c|c|c|c|c|c|}
\hline 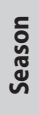 & 苋 & $\begin{array}{l}\stackrel{\Xi}{\alpha} \\
\frac{\pi}{\alpha}\end{array}$ & 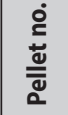 & $\stackrel{\stackrel{\dot{c}}{x}}{\underset{\alpha}{\alpha}}$ & $\overrightarrow{\frac{\alpha}{q}}$ & $\frac{1}{n}$ & そ̌ & 언 & $\geqq$ & $\underset{\nwarrow}{\mathbb{q}}$ & 금 & ণ্ডে & 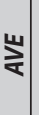 & $\stackrel{m}{\sim}$ & 㟔 & 일 & 잉 & $\checkmark$ & $\vec{R}$ & 岃 & $\vec{ष}$ & $\Sigma$ & $\vec{n}$ & $\tilde{\sim}$ & 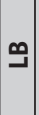 & $\infty$ \\
\hline \multirow{11}{*}{ 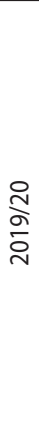 } & 16.11.2019 & par & 105 & 123 & 72 & 35 & 7 & 6 & 0 & 0 & 0 & 0 & 1 & 1 & 0 & 0 & 0 & 0 & 0 & 0 & 0 & 0 & 0 & 1 & 0 & 0 \\
\hline & 05.12.2019 & par & 150 & 161 & 117 & 32 & 4 & 4 & 0 & 0 & 0 & 0 & 0 & 2 & 0 & 2 & 0 & 0 & 0 & 0 & 0 & 0 & 0 & 0 & 0 & 0 \\
\hline & 21.12 .2019 & par & 100 & 117 & 82 & 27 & 1 & 4 & 0 & 1 & 0 & 0 & 0 & 1 & 0 & 1 & 0 & 0 & 0 & 0 & 0 & 0 & 0 & 0 & 0 & 0 \\
\hline & 29.12.2019 & par & 90 & 91 & 61 & 24 & 0 & 3 & 0 & 0 & 0 & 0 & 0 & 2 & 0 & 0 & 0 & 0 & 0 & 1 & 0 & 0 & 0 & 0 & 0 & 0 \\
\hline & 11.01 .2020 & par & 107 & 95 & 63 & 19 & 3 & 0 & 1 & 0 & 2 & 0 & 0 & 2 & 0 & 4 & 0 & 0 & 0 & 0 & 1 & 0 & 0 & 0 & 0 & 0 \\
\hline & 25.01 .2020 & par & 107 & 104 & 60 & 30 & 4 & 3 & 0 & 1 & 0 & 0 & 0 & 4 & 0 & 0 & 0 & 0 & 0 & 0 & 1 & 0 & 0 & 1 & 0 & 0 \\
\hline & 16.02 .2020 & par & 190 & 192 & 109 & 63 & 3 & 8 & 0 & 1 & 0 & 0 & 0 & 0 & 0 & 4 & 0 & 0 & 1 & 0 & 0 & 2 & 0 & 0 & 0 & 1 \\
\hline & 01.03 .2020 & par & 100 & 79 & 54 & 23 & 0 & 1 & 0 & 0 & 0 & 0 & 0 & 0 & 1 & 0 & 0 & 0 & 0 & 0 & 0 & 0 & 0 & 0 & 0 & 0 \\
\hline & 25.01 .2020 & sch & 150 & 160 & 92 & 42 & 4 & 11 & 0 & 0 & 1 & 0 & 0 & 4 & 1 & 1 & 0 & 0 & 1 & 1 & 1 & 0 & 1 & 0 & 0 & 0 \\
\hline & 16.02 .2020 & sch & 150 & 157 & 83 & 61 & 1 & 7 & 0 & 0 & 0 & 0 & 0 & 3 & 0 & 1 & 0 & 0 & 0 & 0 & 0 & 1 & 0 & 0 & 0 & 0 \\
\hline & 01.03 .2020 & sch & 80 & 73 & 44 & 27 & 1 & 0 & 0 & 0 & 0 & 0 & 0 & 0 & 0 & 0 & 0 & 0 & 1 & 0 & 0 & 0 & 0 & 0 & 0 & 0 \\
\hline \multicolumn{3}{|c|}{ TOTAL } & 4683 & 5265 & 3811 & 1154 & 59 & 128 & 9 & 9 & 4 & 1 & 2 & 22 & 2 & 36 & 5 & 1 & 3 & 2 & 3 & 3 & 1 & 6 & 2 & 2 \\
\hline
\end{tabular}

Table 3. Comparison of the results of Long-eared Owl pellet analyses in Békés County in the 1960s and 1970s (source: Schmidt 1980) with the results of this study

3.táblázat A Békés megyében az 1960-as és 1970-es években végzett bagolyköpet-elemzések eredményeinek (forrás: Schmidt 1980) összehasonlítása a saját vizsgálatunkban talált kisemlősfajok százalékos arányával

\begin{tabular}{|l|c|c|c|c|c|c|}
\hline \multirow{2}{*}{\multicolumn{1}{|c|}{ Prey }} & Békés & \multicolumn{5}{c|}{ Kevermes } \\
\cline { 2 - 7 } & 1960s and 1970s & $\mathbf{2 0 1 6 / 1 7}$ & $\mathbf{2 0 1 7 / 1 8}$ & $\mathbf{2 0 1 8 / 1 9}$ & $\mathbf{2 0 1 9 / 2 0}$ & Total \\
\hline Sorex araneus & 0.05 & 0 & 0 & 0 & 0 & 0 \\
\hline Sorex minutus & 0.1 & 0 & 0 & 0 & 0 & 0 \\
\hline Neomys sp. & 0.01 & 0 & 0 & 0 & 0 & 0 \\
\hline Crocidura suaveolens & 0.7 & 0 & 0 & 0 & 0 & 0 \\
\hline Crocidura leucodon & 0.5 & 0 & 0.2 & 0 & 0.2 & 0.08 \\
\hline Muscardinus avellanarius & 0.03 & 0 & 0 & 0.03 & 0.07 & 0.04 \\
\hline Microtus subterraneus & 1.5 & 0 & 0 & 0.1 & 1.41 & 0.4 \\
\hline Microtus arvalis & 56.4 & 66.9 & 58.5 & 80.9 & 61.9 & 72.4 \\
\hline Arvicola amphibius & 0.02 & 0 & 0 & 0 & 0 & 0 \\
\hline Micromys minutus & 2.4 & 0 & 1.8 & 0 & 0.07 & 0.17 \\
\hline Apodemus sylvaticus & 24.6 & 26.7 & 34.4 & 18.8 & 28.8 & 21.9 \\
\hline Apodemus agrarius & 1.6 & 4.2 & 3.3 & 1.5 & 3.47 & 2.4 \\
\hline Mus spicilegus/musculus & 12.2 & 1.8 & 1.1 & 0.5 & 2.1 & 1.1 \\
\hline Rattus sp. & 0.02 & 0.4 & 0.7 & 0.03 & 0.2 & 0.17 \\
\hline Cricetus cricetus & 0 & 0 & 0 & 0.03 & 0 & 0.02 \\
\hline
\end{tabular}


Table 4. The relationships between the ratio of prey animals found in the pellets at the time of collection and the temperatures and snow thickness of the current period. The abbreviated variables are as follows: min. temp: minimum temperature, max. temp: maximum temperature, ave temp: average temperature

4. táblázat $\mathrm{A}$ köpetekben talált zsákmányállatok gyűjtési időpontonkénti aránya és a hőmérséklet és hóvastagság közti kapcsolat az aktuális időszakban. A rövidített időjárási változók a következők: min. temp: legalacsonyabb hőmérséklet, max. temp: legmagasabb hőmérséklet, ave temp: átlaghőmérséklet

\begin{tabular}{|c|c|c|c|c|}
\hline Species & Place & Variable & $\mathbf{R}$ & $\mathbf{p}$ \\
\hline Microtus arvalis & \multirow{15}{*}{ park } & \multirow{5}{*}{ min. temp } & -0.02 & 0.95 \\
\hline Apodemus sylvaticus & & & -0.12 & 0.64 \\
\hline Mus musculus/spicilegus & & & -0.17 & 0.51 \\
\hline Microtus agrestis & & & -0.03 & 0.91 \\
\hline Aves & & & 0.06 & 0.82 \\
\hline Microtus arvalis & & \multirow{5}{*}{ max. temp } & 0.30 & 0.22 \\
\hline Apodemus sylvaticus & & & -0.35 & 0.15 \\
\hline Mus musculus/spicilegus & & & -0.14 & 0.59 \\
\hline Microtus agrestis & & & -0.11 & 0.67 \\
\hline Aves & & & 0.05 & 0.85 \\
\hline Microtus arvalis & & \multirow{5}{*}{ ave temp } & -0.01 & 0.97 \\
\hline Apodemus sylvaticus & & & -0.11 & 0.67 \\
\hline Mus musculus/spicilegus & & & -0.19 & 0.46 \\
\hline Microtus agrestis & & & 0.15 & 0.55 \\
\hline Aves & & & 0.11 & 0.66 \\
\hline Microtus arvalis & \multirow{12}{*}{ school } & \multirow{4}{*}{ min. temp } & 0.41 & 0.33 \\
\hline Apodemus sylvaticus & & & -0.33 & 0.39 \\
\hline Mus musculus/spicilegus & & & 0.30 & 0.49 \\
\hline Microtus agrestis & & & -0.04 & 0.94 \\
\hline Microtus arvalis & & \multirow{4}{*}{ max. temp } & 0.55 & 0.17 \\
\hline Apodemus sylvaticus & & & -0.43 & 0.27 \\
\hline Mus musculus/spicilegus & & & 0.41 & 0.33 \\
\hline Microtus agrestis & & & -0.33 & 0.42 \\
\hline Microtus arvalis & & \multirow{4}{*}{ ave temp } & 0.47 & 0.22 \\
\hline Apodemus sylvaticus & & & -0.38 & 0.36 \\
\hline Mus musculus/spicilegus & & & 0.27 & 0.36 \\
\hline Microtus agrestis & & & -0.15 & 0.73 \\
\hline Microtus arvalis & \multirow{5}{*}{ school + park } & \multirow{5}{*}{ snow thickness } & 0.15 & 0.58 \\
\hline Apodemus sylvaticus & & & 0.01 & 0.98 \\
\hline Mus musculus/spicilegus & & & -0.10 & 0.70 \\
\hline Microtus agrestis & & & -0.39 & 0.13 \\
\hline Aves & & & -0.21 & 0.45 \\
\hline
\end{tabular}


Table 5. The maximum number of Long-eared Owls observed in different winter seasons, the dates of these observations, and the starting and ending of wintering in each season

5. táblázat A különböző téli szezonokban észlelt maximális erdei fülesbagoly példányszámok, azok időpontjai, ill. a gyülekező madarak megjelenésének és távozásának időpontjai az adott szezonban

\begin{tabular}{|c|c|c|c|c|}
\hline Season & Max. number & Date of max. number & Start of wintering & End of wintering \\
\hline $2002 / 03$ & 120 & - & - & - \\
\hline $2012 / 13$ & 11 & 02.03 .2013 & late September & late March \\
\hline $2013 / 14$ & 30 & 27.12 .2013 & late October & mid-February \\
\hline $2014 / 15$ & 40 & 01.12 .2014 & mid-October & early April \\
\hline $2015 / 16$ & 70 & 14.11 .2015 & late October & early March \\
\hline $2016 / 17$ & 70 & 08.01 .2017 & mid-October & early March \\
\hline $2017 / 18$ & 15 & 19.11 .2017 & mid-September & mid-March \\
\hline $2018 / 19$ & 40 & 10.12 .2018 & mid-October & mid-March \\
\hline $2019 / 20$ & 27 & 25.01 .2020 & mid-September & mid-March \\
\hline
\end{tabular}

found in the pellets was not related to the number of roadkilled owls $(R=-0.32, p=0.95)$. Within a year, the number of roadkilled birds shows a clear peak in June (Figure 2). Most individuals (7-7) were found in 2014 and 2016, while in 2012, no roadkilled bird was detected (Figure 3).

\section{Discussion}

The Long-eared Owl, in contrast to the Barn Owl (Tyto alba), is a selective hunter (Mikkola 1983). The diet of the Long-eared Owl includes different animal species in different geographical regions, but voles are dominant in most places (Schmidt 1975). In Northern Europe and the British Isles, the Microtus species (Hagen 1969, Glue \& Hammond 1974), in Southern Europe the House Mouse (Kontogeorgos et al. 2019), while in Central and Eastern Europe, including Hungary, the Common Vole is the dominant prey (Schmidt 1975, Kalotás 1998, Stasiak et al. 2018).

Common Voles accounted for more than $60 \%$ of the diet of Long-eared Owls nesting and wintering in Hungary (Schmidt 1965). According to Schmidt (1973), the proportion of prey animals, such as Common Vole, also varies within the country. The highest proportion (85.7\%) was found in North-Northeast Hungary, while the lowest proportion (53.9\%) was found in the Great Hungarian Plain. However, there was no significant difference between the proportion of Common Voles in the collected literature and our results. In our study, at all three collection sites and in all seasons, Common Voles were the dominant species. The proportion of Common Vole varied between 58.5\% (2017/18) and 80.9\% (2018/19) in our samples. Since the population of Common Voles grows in a gradual manner every 3-4 years and then collapses for natural reasons (Schmidt 1968, Bihari 2007), the differences obtained are due to their population dynamics. 


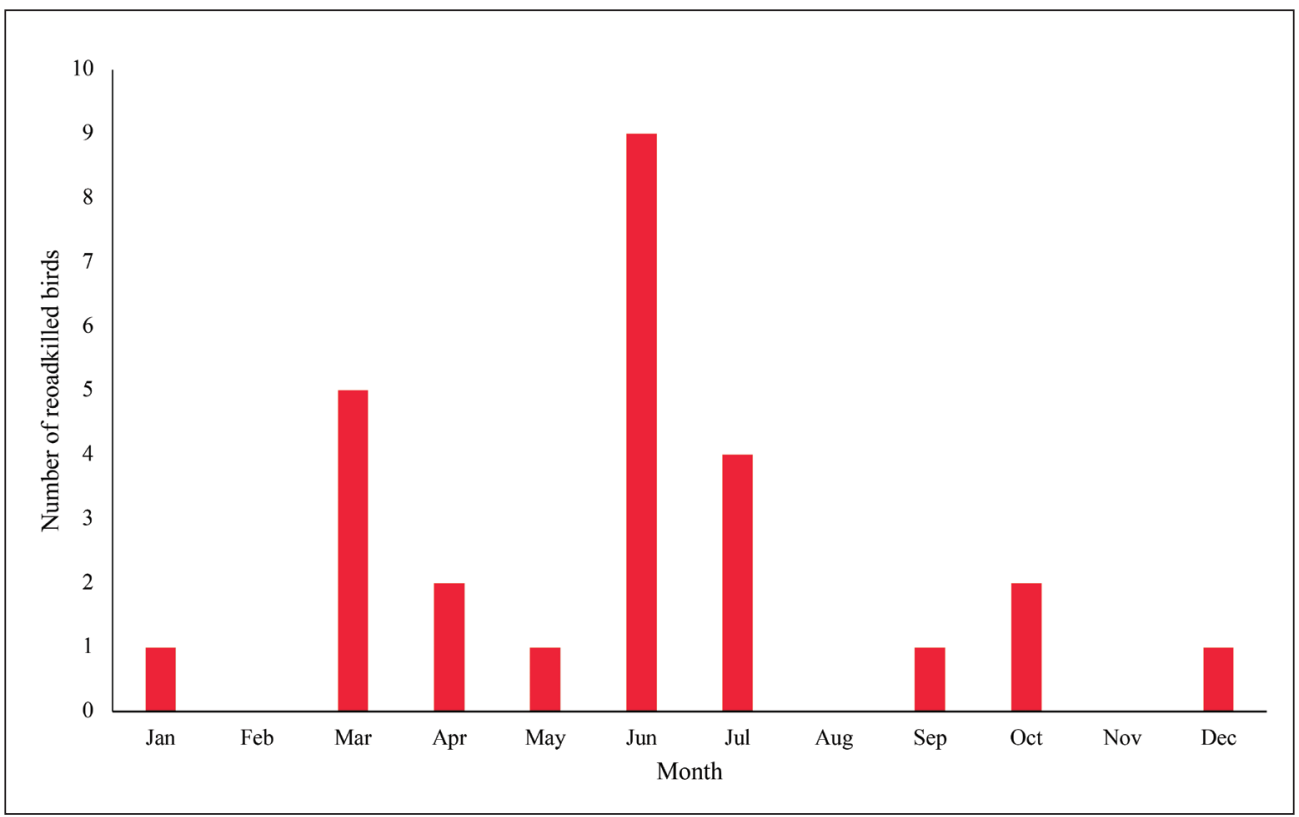

Figure 2. Monthly distribution of roadkilled Long-eared Owls found in Battonya between 2012-2019 2. ábra A Battonyán 2012 és 2019 között talált, elütött erdei fülesbaglyok száma havi bontásban

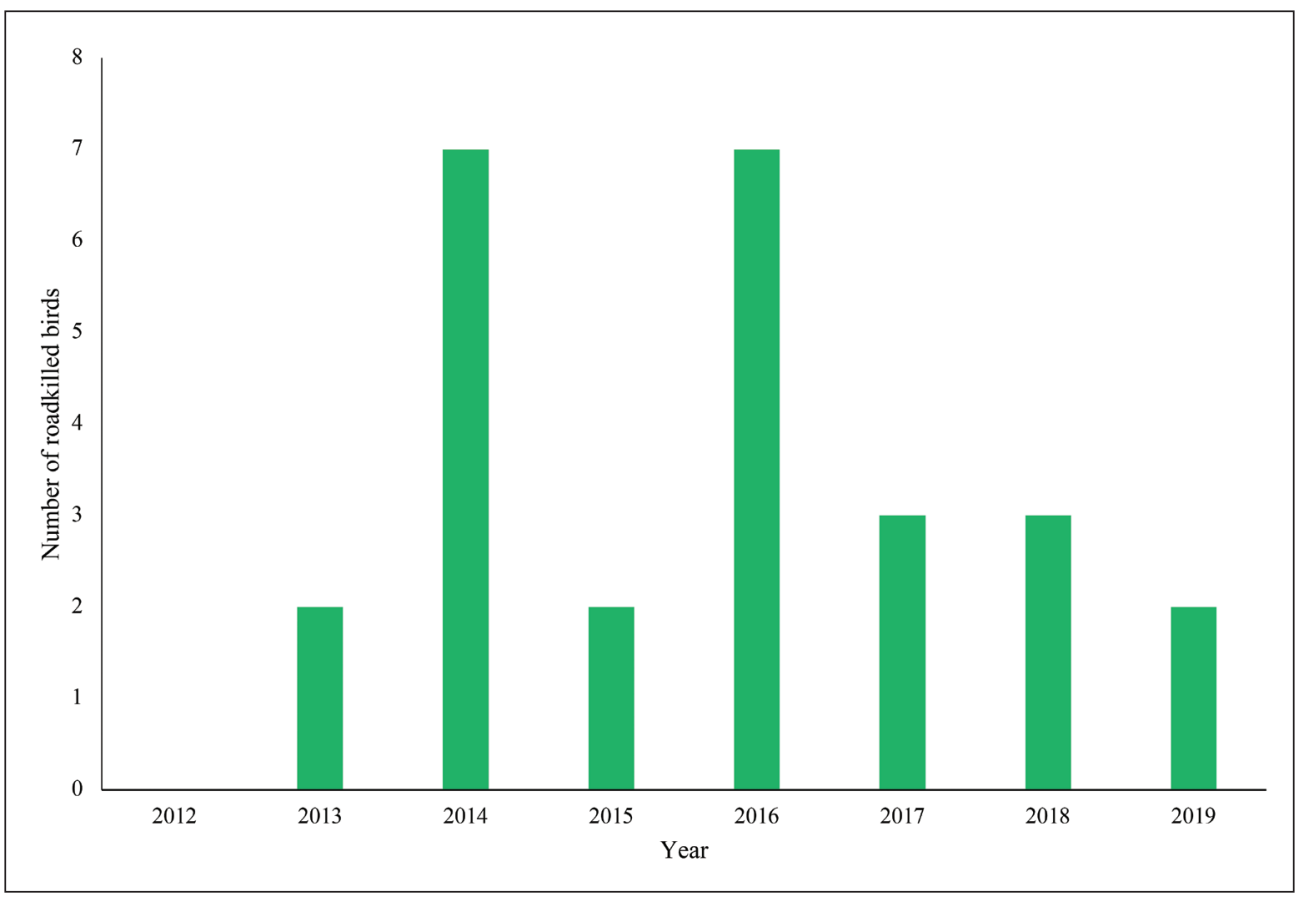

Figure 3. Annual distribution of roadkilled Long-eared Owls found in Battonya between 2012-2019 3. ábra A Battonyán 2012-2019 között talált, elütött erdei fülesbaglyok száma éves bontásban 
In the gradation years, Long-eared Owls can breed up to two times (Haraszthy 2019), so the local number of individuals of the species obviously increases, which should also be reflected in the number of individuals roosting in the area and hit on the road. Out of the four winter seasons of the study period, the number of wintering owls was highest in the year of gradation (2018), but no correlation was found between the number of roosting individuals and the proportion of Common Voles in the pellets, neither between the number of roadkilled owls and the number of wintering individuals. However, the fewest Long-eared Owls were in the area when the proportion of Common Voles in the diet was the lowest during the four study years. This is due to the fact that owls may not be able to breed in food-poor years, and in extreme cases may even disappear from the area (Haraszthy 2019). The lack of correlation between the number of wintering birds and winter weather may confirm the assumption that the number of birds is mainly related to the annual breeding success.

Owl pellet analyses, together with roadkill surveys, were carried out in Battonya in 1998 and 1999 (Csathó \& Csathó 2009). Based on the number of roadkilled individuals, the last significant gradation of the Common Vole occured in 2014, although the results of pellet analyses show a definite gradation in 2018. This discrepancy indicates that the two methods do not necessarily lead to similar results. Further studies are needed to explore the causes. It is conceivable that, although the geographical distance between the two areas is very small, somewhat different methods are used in agriculture, which may lead to the differences.

In addition to the Common Vole, the proportion of Wood Mouse species was also significant in the prey (on average about $25 \%$ ). This proportion is much higher than indicated by the collected literature on the Carpathian Basin (about 12\%) (Table 2) and contradicts the fact that the proportion of Wood Mice is higher in forested areas (Bihari 2007). Csathó and Csathó (2009) found the proportion of roadkilled Wood Mice to be $31.9 \%$ in 1998 and 1999, which also indicates that Apodemus species are present in high proportions in the area.

The Striped Field Mouse was the third prey animal to be found in the pellets at a rate of over $1 \%$ each year. This species, similar to Wood Mouse species, was present in a somewhat higher proportion in the samples we collected than considering the entire area of the Carpathian Basin. This can certainly be explained by the fact that Striped Field Mouse are more common in the eastern parts of the Great Hungarian Plain than elsewhere (Schmidt 1969).

Radiotelemetry studies show that Long-eared Owls typically roam 185-370 hectares per night during the winter season (Wijnandts 1984). According to the studies of Gyovai (1986), the variability of prey in Csongrád County varied depending on the type of soil. Large monoculture arable land, characterized by hard ground, reduces the diversity of small mammals and causes dominance of Common Voles, while alluvial soils are home to a much more diverse vegetation cover with diverse small mammal fauna. In view of these findings, it is not surprising that the percentage distribution of prey animals did not change during the season. In Kevermes, monocultural arable lands are typical, where the diversity of small mammals is low and owls do not have the opportunity to prey in other types of habitats. 
The most varied food spectrum was found in the 2019/20 season, when least snow fell in the study area. The species typically prey on higher numbers of birds in snowy winters (Schmidt 1965), however, due to the collapse of the Common Vole population, the proportion of other species, such as birds and other small mammals had to be increased regardless of snow thickness. In addition, due to the mild winter, several bird species were present in larger numbers in the area, which normally migrate to the south, thus increasing the likelihood of bird prey. A good example of this is the White Wagtail (Motacilla alba), as this species typically leave the area by the end of October (Bozó 2017). However, in the 2019/2020 season, we still saw two individuals in the area on the $17^{\text {th }}$ of November (Bozó L. pers. obs.).

We have found species that are not considered common in the area. Two data of Hazel Dormouse have been known so far from Kevermes (Bozó 2018) and 12 published data exist from Battonya (Csathó \& Csathó 2009, 2014). The two individuals found in the pellets provide further evidence that the Hazel Dormouse may be present in this less-forested area. Furthermore, during the national population survey of the Hazel Dormouse, there were data only from North Békés, the Körös region, not from the southern parts dominated by agricultural areas (Hecker et al. 2003, Bihari 2007).

Based on data of owl pellet analyses, the Eurasian Harvest Mouse is widespread in Hungary (Váczi et al. 2019). In Kevermes, it occurred in only two seasons during the study period, the cause of which is not obvious, but perhaps due to the fact that the species occurs only on certain, fragmented habitats that are further away from the typical hunting territories of the owls. This is why it was found only in the samples of a season when Long-eared Owls widen the hunting area and visit these small fragmented habitats.

The situation may be similar for European Pine Vole, a widespread species in Hungary mainly in the central and southern parts of Transdanubia, while in the Great Plain it is especially rare (Schmidt 1974c). According to Schmidt (1974c), the species also occurred in Battonya and Mezőhegyes in the early 1970s. Perhaps, we witnessed such a gradation during the 2019/20 season, when far more European Pine Voles were found in the pellets than in the previous season.

Definitely, it is worth mentioning the European Hamster, which is very rarely found in Longeared Owl pellets. In the literature from the Carpathian Basin (Table 1), only one indiviual was found in a pellet collected in 1984 at the botanical garden in Dunaszentmiklós (Dániel et al. 1986). The species is rare prey of Long-eared Owls because of its large body size.

Compared to the 1960s and 1970s, we detected an order of magnitude fewer House/ Steppe Mice in the current study. Although the two species differ significantly in their behavior and habitat (Barkasi \& Zagorodniuk 2016), they are morphologically very difficult to separate, so usually treated together. The change in the number of House/Steppe Mice in the last decades may certainly be due to changes in agricultural cultivation (increase in parcel size, change in cultivated plant varieties, increased use of chemicals, more modern, less environmentally friendly tillage technologies). In addition, there were significant changes in the storage of crops, which may have caused a significant decline in the number of House Mouse. Until the early 2000s, maize was mainly stored in open granaries, but this method has completely disappeared and the harvested grain is placed in closed granaries. In contrast, the number of rats in the pellets increased, which may be related to the unfavorable 
human demographic conditions in the area. With the slow depopulation of settlements, more and more abandoned houses are serving as excellent habitats for the rats. Negative demographics also affect the local population of another owl species, the Little Owl (Athene noctua), which increased significantly in the area over the last decade thanks to more and more abandoned houses that provide a quiet nesting place and excellent feeding ground for the species (Bozó \& Csathó 2017).

Birds also appeared regularly in the pellets. The proportion of bird prey was similar to that obtained in studies in other areas of the Carpathian Basin with a rate of $2.7 \%$ (Table 1). The dominant species was the Eurasian Tree Sparrow, which is also the most dominant bird prey in the Carpathian Basin (Table 1).

During the four years of the study, no bats were found in the pellets. This is interesting because the Long-eared Owl regularly prey on small numbers of bats (Schmidt \& Topál 1971, Ujhelyi 1991), and many bats can be found in the study area until November.

The first Long-eared Owls typically appeared in the roosting sites in October, but often some birds were already there in September. Since winter roosting sites are first occupied by members of the local population (Wijnandts 1984), it can be assumed that these early individuals may have breed in the park and its immediate vicinity. The species also breeds increasingly in human settlements in Hungary (Kovács 2015, Haraszthy 2019). The roosting sites were typically left until early to mid-March, with later observations likely to apply to members of the local population. This is because the species starts breeding early in the spring, the clutch become complete in early April, but they can breed as early as March, sometimes even in winter (Balogh 2006, Monoki 2010).

According to the roadkill data, the largest number of Long-eared Owls were hit by the traffic in the summer period after the independence of the young birds (June - July). Similar results were obtained by Bozó and Csathó (2017) in case of Little Owl, with the difference that the maximum number of roadkilled individuals were found in the second half of the summer (July - August).

Based on the maximum number of individuals counted in the roosting sites, it is likely that the species was a more common breeder in Kevermes in the early 2000s than in the 2010s. The reason for the decline may be the drastic local population decline of the Common Magpie (Pica pica) and the Hooded Crow (Corvus cornix) (Bozó 2017), which are the most important host species whose nest are occupied by Long-eared Owls. In addition, cutting of older tree lines and forest patches may contribute to this process, further reducing the likelihood of nesting. The disappearance of corvids and nesting sites cannot be compensated even by the urbanization of the species. However, the period from 2010 to 2020 does not indicate a trend-like decrease in Kevermes and Battonya either. The changes experienced occurred from one year to the next. These changes draw attention to the fact that there may be differences even between close areas with similar geographical features, and it is not possible to draw general, landscape-level conclusions from studies of a narrower region. It should also be noted that although there was no significant correlation between the number of roadkilled birds and the amount of bird observed in the roosting sites, similarities could be detected between the data sets. Between 2012 and 2014, an increasing trend can be observed in both data series, while between 2016 and 2019 the trends were decreasing. 


\section{Acknowledgements}

We would like to thank to András János Csathó for his help in the survey of roadkilled animals, and to Tibor Csörgö for reviewing the early version of the manuscript and for his useful suggestions.

\section{References}

Ács, A. 1986. Néhány adat a Zala megyében telelő erdei fülesbaglyok (Asio otus) táplálkozásáról [Some data on the feeding of Long-eared Owls (Asio otus) wintering in Zala County]. - Madártani Tájékoztató 10(1): 7678. (in Hungarian)

Andrési, P. \& Sódor, L. 1981. A zsákmányállatok megoszlása fülesbagoly (Asio otus) köpetekben talált maradványok alapján [Distribution of prey animals based on residues found in Nortnern Long-eared Owl (Asio otus) pellets]. - Madártani Tájékoztató 5(4): 233-234. (in Hungarian)

Andrési, P. \& Sódor, M. 1987. Sopron és környékének kisemlős faunája. I. rész [The small mammal fauna of Sopron and its surroundings, Part I.]. - Soproni Szemle 41(3): 211-225. (in Hungarian)

Balogh, Gy. 2006. Városi fülesbaglyok [Urban Long-eared Owls]. - Madártávlat 13(1-2): 30-31. (in Hungarian)

Barkasi, Z. \& Zagorodniuk, I. 2016. The taxonomy of rodents of the Eastern Carpathians. - Scientific Notes of the State Museum of Natural History 32: 137-154.

Bessenyei, B., Dudás, M. \& Sándor, I. 1983. Adatok az erdőspusztán fészkelő bagolyfajok táplálkozásának ismeretéhez [Data for the knowledge of the feeding of owl species nesting in the forest steppe]. - Madártani Tájékoztató 7(3-4): 112-113. (in Hungarian)

Bihari, Z. 2007. Magyarország emlőseinek atlasza [Atlas of the mammals of Hungary]. - Kossuth Kiadó, Budapest (in Hungarian)

BirdLife International 2020. Species factsheet: Asio otus. - http://www.birdlife.org on 03/08/2020.

Bozó, L. 2017. Kevermes madárvilága [Birds of Kevermes]. - Dél-békési Természetvédelmi és Madártani Egyesület, Kevermes (in Hungarian with English Summary)

Bozó, L. \& Csathó, A. I. 2017. The status and population changes of the Little Owl (Athene noctua) in the south of Békés County (Hungary). - Ornis Hungarica 25(2): 23-33. DOI: 10.1515/orhu-2017-0013

Bozó, L. 2018. Dél-Békés természeti értékei [Nature assets of South-Békés]. - Dél-békési Természetvédelmi és Madártani Egyesület, Kevermes (in Hungarian)

Csathó, A. I. \& Csathó, A. J. 2009. Elütött állatok Battonyán [Roadkills and the dynamics of the faunal casualties in Battonya (SE Hungary)]. - CSEMETE Természet- és Környezetvédelmi Egyesület, Battonya-Szeged (in Hungarian with English Summary)

Csathó, A. I. \& Csathó, A. J. 2014. Az idén huszadik éves battonyai elütöttállat-felmérés legutóbbi öt évének (2010-2014) adatai [Data of the past five years (2010-2014) of the twentieth year old roadkill surveys in Battonya]. - In: Lengyel, Sz. (ed.) IX. Magyar Természetvédelmi Biológiai Konferencia. - „Tudományoktól a döntéshozatalig”. - Absztrakt-kötet. - Magyar Biológiai Társaság - Szegedi Tudományegyetem Ökológiai Tanszék - MTA Ökológiai Kutatóközpont, Szeged, pp. 45-46. http://www.mtbk.hu/mtbk09/doc/IX.MTBK AbsztraktKotet.pdf (in Hungarian)

Csizmazia, Gy. 1966. Beiträge zur Fledermaus-Fauna des Ungarischen Tisza-Tales [Contributions to the bat fauna of the Hungarian Tisza Valley]. - Tiscia 2: 127-130. (in German)

Dániel, Á., Frank, T. \& Pellinger, A. 1986. Erdei fülesbagoly (Asio otus) táplálékának vizsgálata [Examination of the diet of the Long-eared Owl (Asio otus)]. - Madártani Tájékoztató 10(1): 79. (in Hungarian)

Endes, M. 1986. Bagolytáplálkozási megfigyelések [Observations on feeding of owls]. - Madártani Tájékoztató 10(1): 78. (in Hungarian)

Glue, D. E. \& Hammond, G. J. 1974. The feeding ecology of the Long-eared Owl in Britain and Ireland. British Birds 67: 361-369.

Glutz von Blotzheim, U. N. \& Bauer, K. M. 1980. Handbuch der Vögel Mitteleuropas, Band 9. Columbiformes Piciformes [Handbook of the birds of Central Europe, Vol. 9. Columbiformes - Piciformes]. - Akademische Verlagsgesellschaft, Wiesbaden (in German)

Greschik, J. 1911. Hazai ragadozómadaraink gyomor- és köpettartalom vizsgálata. II. Baglyok [Studies on the stomach and pellet content of the Hungarian birds of prey. II. Owls]. - Aquila 18: 141-177. (in Hungarian and German) 
Gyovai, F. 1986. Telelő erdei fülesbaglyok (Asio otus) demográfiai vizsgálata Csongrád megyében [Population studies on overwintering Long-eared Owls (Asio otus) in Csongrád County, Hungary]. - MME II. Tudományos Ülése, Szeged, pp. 301-311. (in Hungarian with English Summary)

Gyovai, F. 2020. Bagolyleltár. Telelő erdei fülesek demográfiai vizsgálata [Owl control. Demographic study of wintering Long-eared Owls]. - Élet és Tudomány (10): 302-304. (in Hungarian)

Hagen, Y. 1969. Norwegian studies on the reproduction of birds of prey and owls in relation to micro-rodent population fluctuations. - Fauna 22: 73-126.

Hammer, Ø., Harper, D. A. \& Ryan, P. D. 2001. PAST: Paleontological statistics software package for education and data analysis. - Palaeontologia Electronica 4(1): 9.

Haraszthy, L. 2019. Magyarország fészkelő madarainak költésbiológiája. 1. kötet. Fácánféléktől a sólyomfélékig [Breeding biology of Hungarian nesting birds, Vol. 1. Non-Passeriformes]. - Pro Vértes Nonprofit Kft., Csákvár, pp. 679-683. (in Hungarian)

Hecker, K., Bakó, B. \& Csorba, G. 2003. Distribution ecology of the Hungarian dormouse species, based on the national biodiversity monitoring system. - Acta Zoologica Academiae Scientiarum Hungaricae 49(Suppl.1.): $45-54$.

Kalivoda, B. 1987. Adatok az erdei fülesbagoly (Asio otus) táplálkozásához [Data on the feeding of the Longeared Owl (Asio otus)]. - Madártani Tájékoztató 11(3-4): 27. (in Hungarian)

Kalivoda, B. 1994. Adatok az erdei fülesbagoly (Asio otus) táplálkozásához [Data on the feeding of the Longeared Owl (Asio otus)]. - Madártani Tájékoztató 18(1): 14. (in Hungarian)

Kalivoda, B. 1999a A magyar bagoly-táplálkozástani irodalom annotált bibliográfiája [The annoted bibliography of the Hungarian literature on owl food]. - Crisicum 2: 221-254. (in Hungarian with English Summary)

Kalivoda, B. 1999b Adatok a Karcagi Arborétumban telelő erdei fülesbaglyok (Asio otus) táplálkozásáról [Data on the feeding of Long-eared Owls (Asio otus) wintering in the Karcag Arboretum]. - A Puszta 16: 101102. (in Hungarian)

Kalotás, Zs. 1998. Erdei fülesbagoly [Long-eared Owl]. - In: Haraszthy, L. (ed.) Magyarország madarai [Birds of Hungary]. - Mezőgazda Kiadó, Budapest, pp. 221-222. (in Hungarian)

Kessler, J. 2015. Osteological guide of songbirds from Central Europe. - Ornis Hungarica 23(2): 62-155. DOI: 10.1515/orhu-2015-0016

Kontogeorgos, I., Kiamos, N., Montiel-Ruiz, P., Georgopoulou, E., Mylonas, M. \& Xirouchakis, S. M. 2019. Feeding ecology and prey selection by wintering Long-eared Owls Asio otus in Mediterranean agrosystems. - Ornithological Science 18(1): 95-110. DOI: 10.2326/osj.18.95

Kovács, Á. 2015. Telelő erdei fülesbaglyok (Asio otus) nappalozási szokásaira vonatkozó preferencia vizsgálatok városi gyülekezöhelyeken [Studies on the roosting habits of wintering Long-eared Owls (Asio otus) in urban roosting sites]. - A Puszta 25: 185-215. (in Hungarian)

Köves, E. O. \& Schmidt, E. 1964. Adatok Tornyosnémeti környéke kisemlősfaunájának ismeretéhez bagolyköpetvizsgálatok alapján [Data for the knowledge of the small mammal fauna of Tornyosnémeti and its surroundings based on owl pellets]. - Vertebrata Hungarica 6(1-2): 97-108. (in Hungarian with German Summary)

Laczik, D. \& Sebe, K. 2009. Erdei fülesbagoly [Long-eared Owl]. - In: Csörgő, T., Karcza, Zs., Halmos, G., Magyar, G., Gyurácz, J., Szép, T., Bankovics, A., Schmidt, A. \& Schmidt, E. (eds.) Magyar madárvonulási atlasz [Hungarian Bird Migration Atlas]. - Kossuth Kiadó Zrt., Budapest, pp. 366-368. (in Hungarian with English Summary)

Lambrecht, K. 1914. Adatok a karvaly és az erdei fülesbagoly táplálékának ismeretéhez [Data for the knowledge of the feeding of the Eurasian Sparrowhawk and the Long-eared Owl]. - Aquila 21: 275. (in Hungarian and German)

Marián, M. \& Marián, O. 1973. Anuren-Knochenreste aus Eulengewöllen [Remnants of anuric bones from owl pellets]. - Vertebrata Hungarica 14: 9-18. (in German with Hungarian and English Summary)

Mátics, R. 1990. Bagolyköpet vizsgálatok [Studies on owl pellets]. - Madártani Tájékoztató 14(3-4): 30-31. (in Hungarian)

Mikkola, H. 1983. Owls of Europe. - T \& AD Poyser, Calton

Molnár, I. 1983. Bagolytáplálkozási adatok a Dunántúlról [Data on the feeding of owls from Transdanubia]. Madártani Tájékoztató 7(3-4): 106-110. (in Hungarian)

Molnár, I. 1994. Erdei fülesbagoly (Asio otus) táplálkozási adatai Zircröl [Feeding data of the Long-eared Owl (Asio otus) from Zirc]. - Madártani Tájékoztató 18(2): 33. (in Hungarian)

Molnár, L. 2010. Adatok az erdei fülesbagoly (Asio otus L.) téli táplálkozásához Sepsiszentgyörgyön köpetvizsgálatok alapján [Contributions to the dietary habits in winter of the Long-eared Owl (Asio otus L.) in 
Sepsiszentgyörgy (Sf. Gheorghe)]. - Acta Siculica 2011-2012: 145-153. (in Hungarian with English and Romanian Summary)

Monoki, Á. 2010. Erdei fülesbaglyok (Asio otus) városi és laza telepes fészkelése [Urban and loose colony nesting of Eurasian Long-eared Owls (Asio otus)]. - A Puszta 23: 290-291. (in Hungarian)

Nagy, S. 1982a A zsákmányállatok megoszlása fülesbagoly (Asio otus) köpetekben talált maradványok alapján [Distribution of prey animals based on residues found in Eurasian Long-eared Owl (Asio otus) pellets]. - Madártani Tájékoztató 6(2-3): 113. (in Hungarian)

Nagy, S. 1982b A zsákmányállatok megoszlása fülesbagoly (Asio otus) köpetekben talált maradványok alapján [Distribution of prey animals based on residues found in Eurasian Long-eared Owl (Asio otus) pellets]. - Madártani Tájékoztató 6(4): 304. (in Hungarian)

Papp, J. L. 1971. Aranyosgadány kisemlősfaunája gyüjtések és bagolyköpet vizsgálatok alapján [The small mammal fauna of Aranyosgadány based on collecting and the examination of regurgitated owl pellets]. Vertebrata Hungarica 12: 69-78. (in Hungarian with English Summary)

Pótis, L. 1992. Adatok az erdei fülesbagoly (Asio otus) teleléséhez Ungváron (Uzgorod) és környékén [Data for the wintering of the Long-eared Owl (Asio otus) in and around Ungvár (Uzhhorod)]. - Madártani Tájékoztató 16(2): 26. (in Hungarian)

Schaefer, H. 1935. Inhalte einiger Eulengewölle aus Südungarn [Contents of some owl pellets from southern Hungary]. - Acta Biologica 3(3): 226-229. (in German)

Schmidt, E. 1965. Über die Winternahrung der Waldohreulein der VR Ungarn [About the winter diet of the Longeared Owl in Hungary]. - Zoologische Abhandlungen MuseumTierkunde Dresden 27: 307-317. (in German)

Schmidt, E. 1968. A Magyarországon telelő erdei fülesbaglyok mezei pocok pusztításának elméleti értékelése köpetvizsgálatok alapján [Studies on the Common Vole predation by Long-eared Owls wintering in Hungary based on pellets]. - Aquila 75-77: 259-271. (in Hungarian and German)

Schmidt, E. 1969. Adatok egyes kisemlősfajok elterjedéséhez Magyarországon, bagolyköpet vizsgálatok alapján (Elözetes jelentés) [Data on the distribution of certain small mammal species in Hungary, based on owl pellets (Preliminary report)]. - Vertebrata Hungarica 9: 137-153. (in Hungarian with German Summary)

Schmidt, E. 1973. A gyöngybagoly (Tyto alba) és az erdei fülesbagoly (Asio otus) legfontosabb táplálékállatai Magyarországon [The most important preys of Barn Owl (Tyto alba) and Long-eared Owl (Asio otus)]. Aquila 76-77: 55-64. (in Hungarian with German Summary)

Schmidt, E. 1974a A magyarországi mezei pocok (Microtus arvalis) állomány relatív sürüsége 1969-71-ben bagolyköpetek vizsgálata alapján [The relative population density of Common Vole (Microtus arvalis) between 1969-71 on the basis of owl pellets]. - Aquila 78-79: 189-196. (in Hungarian with German Summary)

Schmidt, E. 1974b Adatok Vas megye kisemlősfaunájához baglyok táplálékvizsgálata alapján [Data for the small mammal fauna of Vas County based on the analysis of owl pellets]. - Savaria (Vas megyei Múzeumok Értesítője) 7-8: 71-77. (in Hungarian with German Summary)

Schmidt, E. 1974c Über die Verbreitung und Wohndichte der Kleinwühlmaus (Pitymys subterraneus (De Selys-Longchamps)) in Ungarn [About the distribution and population density of the European Pine Vole (Pitymys subterraneus (De Selys-Longchamps)) in Hungary]. - Vertebrata Hungarica 15: 45-52. (in German with English Summary)

Schmidt, E. 1975. Az erdei fülesbagoly táplálkozása Európában [The diet of Long-eared Owls in Europe]. - Aquila 80-81: 221-238. (in Hungarian with German Summary)

Schmidt, E. 1978. Adatok a Szigligeti Arborétum és környékének kisemlősfaunájához erdei fülesbagoly (Asio otus) köpetvizsgálatok alapján [Data for the small mammal fauna of the Szigliget Arboretum and its surroundings based on the analyses of pellets of Long-eared Owl (Asio otus)]. - Veszprém megyei Múzeumok Közleményei 13: 123-127. (in Hungarian with German Summary)

Schmidt, E. 1980. Adatok Békés megye kisemlősfaunájához baglyok táplálékvizsgálata alapján [Data for the small mammal fauna of Békés County based on the feeding analysis of owls]. - Békés Megyei Múzeumok Közleményei 6: 179-188. (in Hungarian)

Schmidt, E. 1987. Erdei fülesbaglyok (Asio otus) a Gellérthegyen [Long-eared Owls (Asio otus) on Gellért Hill]. - Madártani Tájékoztató 11(1-2): 43-44. (in Hungarian)

Schmidt, E. \& Topál, Gy. 1971. Denevérmaradványok magyarországi bagolyköpetekből [Bat residues from owl pellets in Hungary]. - Vertebrata Hungarica 12: 93-102. (in Hungarian with German Summary)

Szilágyi-Bónizs, M., Cseh, V. \& Maák, I. E. 2016. Erdei fülesbagoly (Asio otus) téli táplálékpreferenciája antropogén élöhelyeken [The food preference of the Long-eared Owl (Asio otus) in anthropogenic habitats]. Acta Scientiarum Transylvanica - Múzeumi Füzetek 23(1): 43-60. (in Hungarian with English Summary) 
Tóth, G. 1992. Újabb adat Csorna környékének kisemlős faunájához [New data on the mammal fauna of the area of Csorna]. - Soproni Szemle 46(2): 179-181.

Ujhelyi, P. 1989. A magyarországi vadonélő emlősállatok határozója (küllemi és csonttani bélyegek alapján) [Key for identification of wild mammals of Hungary (on the base of habitus and features of sceleton)]. - A Magyar Madártani és Természetvédelmi Egyesület (MME) Könyvtára 1. Budapest (in Hungarian)

Ujhelyi, P. 1991. Kisemlős-faunisztikai adatok bagolyköpetekből - denevérek [Small mammal data from owl pellets - bats]. - Madártani Tájékoztató 15(1-2): 23-24. (in Hungarian)

Ujhelyi, P. 2016. Cranial morphology of European passerine bird families (Aves, Passeriformes). - Ornis Hungarica 24(2): 54-77. DOI: 10.1515/orhu-2016-0015

Váczi, O., Varga, I. \& Bakó, B. (eds.) 2019. A Nemzeti Biodiverzitás-monitorozó Rendszer Eredményei II. - Gerinces Állatok [Results of the National Biodiversity Monitoring System II. - Vertebrates]. - Körös-Maros Nemzeti Park Igazgatóság, Szarvas

Varga, L. 1983. Bagolyköpet-vizsgálatok eredményei Vas megyéből [Results of studies on owl pellets from Vas County]. - Madártani Tájékoztató 7(3-4): 111-112. (in Hungarian)

Varga, L. 1984. Bagolyköpetvizsgálatok eredményei Szombathely környékéről [Results of studies on owl pellets from Szombathely and its surroundings]. - Madártani Tájékoztató 8(1): 60-62. (in Hungarian)

Varga, L. 1987. Bagolyköpet-vizsgálati eredmények Vas megyéből [Results of studies on owl pellets from Vas County]. - Praenorica Folia Historico-naturalia 2: 171-174. (in Hungarian with English and German Summary)

Végvári, Zs. \& Konyhás, S. 2003. Az erdei fülesbaglyok (Asio otus) és réti fülesbaglyok (Asio flammeus) telelö állományának felmérése néhány Hortobágy környéki településen 1996-1998 között [Survey of the wintering population of Long-eared Owls (Asio otus) and Short-eared Owls (Asio flammeus) in some settlements around Hortobágy between 1996-1998]. - Aquila 109-110: 103-107. (in Hungarian with English Summary)

Wijnandts, H. 1984. Ecological energetics of the Long-eared Owl (Asio otus). - Ardea 55(1-2): 1-92.

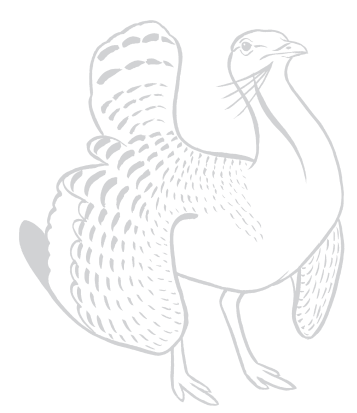

